ARTICLE

DOI: $10.1038 / \mathrm{s} 41467-017-02735-2$

OPEN

\title{
Facile storage and release of white phosphorus and yellow arsenic
}

\author{
Andreas E. Seitz ${ }^{1}$, Felix Hippauf ${ }^{2}$, Werner Kremer ${ }^{3}$, Stefan Kaskel ${ }^{2}$ \& Manfred Scheer (i) ${ }^{1}$
}

The storage of metastable compounds and modifications of elements are of great interest for synthesis and other, e.g., semiconductor, applications. Whereas white phosphorus is a metastable modification that can be stored under certain conditions, storage of the extremely (light- and air-)sensitive form of arsenic, yellow arsenic, is a challenge rarely tackled so far. Herein, we report on the facile storage and release of these tetrahedral $E_{4}$ molecules $(E=P$, As) using activated carbon as a porous storage material. These loaded materials are air- and light-stable and have been comprehensively characterized by solid-state ${ }^{31} \mathrm{P}\left\{{ }^{1} \mathrm{H}\right\}$ MAS NMR spectroscopy, powder X-ray diffraction analysis, nitrogen adsorption measurements, and thermogravimetric analysis. Additionally, we show that these materials can be used as a suitable $\mathrm{E}_{4}$ source for releasing intact white phosphorus or yellow arsenic, enabling subsequent reactions in solution. Because the uptake and release of $E_{4}$ are reversible, these materials are excellent carriers of these highly reactive modifications.

\footnotetext{
${ }^{1}$ Institute of Inorganic Chemistry, University of Regensburg, Universitätsstr. 31, 93040 Regensburg, Germany. ${ }^{2}$ Faculty of Mathematics and Sciences, Discipline of Chemistry and Food Chemistry, Chair of Inorganic Chemistry I, Technical University of Dresden, Bergstr. 66, 01069 Dresden, Germany. ${ }^{3}$ Institute of Biophysics and Physical Biochemistry, University of Regensburg, Universitätsstr. 31, 93040 Regensburg, Germany. Correspondence and requests for materials should be addressed to M.S. (email: manfred.scheer@ur.de)
} 
S ince the discovery of elemental white phosphorus ${ }^{1}\left(\mathrm{P}_{4}\right)$ by Hennig Brand in 1669, it has served as a widely used reagent in academia and industry alike. While activation of the $\mathrm{P}_{4}$ tetrahedron is of great interest in academic research ${ }^{2-5}$, industry is especially interested in the production of organophosphorus compounds and the synthesis of highly pure phosphoric acid starting from white phosphorus. However, solid $\mathrm{P}_{4}$ has to be handled with great care because of its high reactivity, its metastable character and its toxicity, and shipping even small amounts of $\mathrm{P}_{4}$ is subject to severe restrictions. $\mathrm{P}_{4}$ combusts spontaneously in air and decomposes slowly under light. As a result, $\mathrm{P}_{4}$ is stored under water in the dark. In 2009, Nitschke et al. showed the encapsulation of $\mathrm{P}_{4}$ within a self-assembled host-guest complex of iron, which is air-stable in the solid state ${ }^{6}$. The guest can be extracted by better fitting molecules such as benzene and cyclohexane, whereas poor fitting guests, such as $n$-heptane, cannot be used for extraction. Recently, Wu et al. succeeded in storing $\mathrm{P}_{4}$ and, interestingly, also $\mathrm{As}_{4}$ within tetrahedrally shaped cage complexes in solution ${ }^{7,8}$. However, in all these cases, no subsequent reactions with the host-guest complexes were examined due to the resulting multi-component mixtures of the overall systems (occurrence of side reactions). Moreover, the Kawano group showed the encapsulation of $\mathrm{P}_{4}$ in the reusable metal-organic framework $(\mathrm{MOF})\left[\left(\mathrm{ZnI}_{2}\right)_{3}(\mathrm{TPT})\right]_{\mathrm{n}}$ $\left(\mathrm{TPT}=2,4,6\right.$-tris $(4 \text {-pyridiyl)-1,3,5-triazine })^{9}$, again without using them for subsequent syntheses. Here, $\mathrm{P}_{4}$ was synthesized from red phosphorus and trapped by gas phase diffusion. Furthermore, we succeeded in the encapsulation and stabilization of intact tetrahedral $\mathrm{E}_{4}$ molecules $(\mathrm{E}=\mathrm{P}, \mathrm{As})$ in polymeric and spherical aggregates constructed by copper halides and $\left[\mathrm{Cp}{ }^{*} \mathrm{Fe}\left(\eta^{5}-\mathrm{P}_{5}\right)\right]$ $\left(\mathrm{Cp} \mathrm{p}^{*}=\eta^{5}-\mathrm{C}_{5} \mathrm{Me}_{5}\right)^{10}$. Even if the corresponding crystals are air and light-stable, they are insoluble in common solvents and the group 15 tetrahedra are not releasable without the decomposition of the complexes. Moreover, together with other coinage metal $\mathrm{P}_{4}$ complexes, the air-sensitive silver(I) salts $\left[\mathrm{Ag}\left(\eta^{2}-\mathrm{E}_{4}\right)_{2}\right][\mathrm{pftb}]$ $\left(\mathrm{E}=\mathrm{P}, \mathrm{As} ; \mathrm{pftb}=\left[\mathrm{Al}\left\{\mathrm{OC}\left(\mathrm{CF}_{3}\right)_{3}\right\}_{4}\right]\right)$ show to be suitable sources of intact $\mathrm{E}_{4}(\mathrm{E}=\mathrm{P}, \mathrm{As})$ for particular chemical reactions, however with a limited scope due to the need of initial $\mathrm{AgCl}$ elimination ${ }^{11-14}$. Recently, we found two other systems, $\left[(\mathrm{LCu})_{2}\left(\mu, \eta^{2: 2}-\mathrm{E}_{4}\right)\right]\left(\mathrm{E}=\mathrm{P}, \mathrm{As} ; L=\left[\left\{\mathrm{N}\left(\mathrm{C}_{6} \mathrm{H}_{3} i \mathrm{Pr}_{2}-2,6\right) \mathrm{C}(\mathrm{Me})\right\}_{2} \mathrm{CH}\right.\right.$ $\left.\left.{ }^{-}\right]\right)$and $\mathrm{Cp}^{\mathrm{R}} \mathrm{E}_{4}\left(\mathrm{E}=\mathrm{P} ; \quad \mathrm{Cp}^{\mathrm{R}}=\mathrm{Cp}^{*}\left(\eta^{5}-\mathrm{C}_{5} \mathrm{Me}_{5}\right), \mathrm{Cp}^{\prime \prime \prime} \quad\left(\eta^{5}-\right.\right.$ $\left.\mathrm{C}_{5} \mathrm{H}_{3} t \mathrm{Bu}_{2}\right), \mathrm{Cp}^{4 i \mathrm{Pr}}\left(\eta^{5}-\mathrm{C}_{5} \mathrm{HiPr}_{4}\right), \mathrm{Cp}^{\mathrm{BIG}}\left(\eta^{5}-\mathrm{C}_{5}\left(4-n \mathrm{BuC}_{6} \mathrm{H}_{4}\right)_{5}\right) ; \mathrm{E}$ $\left.=\mathrm{As}, \mathrm{Cp}^{\mathrm{R}}=\mathrm{Cp}^{\mathrm{PEt}}\left(\eta^{5}-\mathrm{C}_{5}\left(4-\mathrm{EtC}_{6} \mathrm{H}_{4}\right)_{5}\right)\right)$, which coordinate either side-on the intact $\mathrm{E}_{4}$ tetrahedra or radically opened an $\mathrm{E}-\mathrm{E}$ bond to form a twofold organic-substituted compound with a tetraphospha/tetraarsabicyclo[1.1.0]butane as a central structural motif $^{15-17}$. For both systems, we could show the release of intact $\mathrm{E}_{4}$ tetrahedra, irreversible in solution, but reversible in the solid state for the latter case (except for $\mathrm{E}=\mathrm{As}$ ). However, all known coordinating/encapsulating systems of intact $\mathrm{E}_{4}$ have the disadvantage of a multistep synthesis of the starting materials before the final $\mathrm{E}_{4}$ addition can be executed, which is preparatively time-consuming, expensive, and surely not feasible in large-scale batches. Moreover, the existence of additional reactive components in the solutions after the release of $\mathrm{E}_{4}$ makes these systems unusable for subsequent reactions.

In contrast to white phosphorus, the heavier congener $\mathrm{As}_{4}$ has less been used in industry and academia so far because of its pronounced photosensitivity and its extremely difficult and inconvenient handling. Yellow arsenic, discovered as an element modification 150 years ago ${ }^{18}$, is a metastable compound rapidly decomposing in the solid state even in the dark at low temperatures. Additionally, exposed to light, it decomposes within minutes in solution at room temperature into the thermodynamically stable modification gray arsenic ${ }^{19}$. Whereas solid yellow arsenic can practically not be stored, only solutions of freshly prepared $\mathrm{As}_{4}$ can be used for subsequent reactions ${ }^{20}$, which can, however, only be performed in the absolute dark without any exposure to light whatsoever, and the used amount of $\mathrm{As}_{4}$ is not exactly quantifiable, due to its fast decomposition to gray arsenic. Therefore, the challenging quest arises to develop an easily accessible and light-stable storage and release material for yellow arsenic to open ample perspectives for the usage of this very reactive modification in syntheses and reactivity by a large chemistry community. Keeping in mind the extremely low solubility of $\mathrm{As}_{4}$ at low temperatures, the need for a usable $\mathrm{As}_{4}$ delivery source to overcome this difficulty is obvious. Moreover, for both modifications, the problem of a possible hazard-free shipping has to be solved, which would be a breakthrough regarding their application by both industry and academia.

Herein, we report on the facile storage and release of yellow arsenic and white phosphorus, respectively, using activated carbon as a porous storage material, and on the first use of these materials for subsequent reactions in solutions.

\section{Results}

Preparation. The loaded materials $\mathrm{E}_{4} @ \mathrm{C}(\mathrm{E}=\mathrm{P}, \mathrm{As})$ can be easily prepared by adsorbing $\mathrm{E}_{4}(\mathrm{E}=\mathrm{P}$, As) from a freshly prepared solution in tetrahydrofuran (THF) by an activated carbon material (C) with a defined pore size distribution resulting in an air- and light-stable black solid of $\mathrm{E}_{4} @ \mathbf{C}$ after work-up (Supplementary Figs. 1 and 2).

Release of $\mathbf{E}_{4}$. To study the release of $\mathrm{E}_{4}$ molecules by sublimation, the $\mathrm{E}_{4} @ \mathrm{C}$ (for $\mathrm{E}=\mathrm{P}: 820 \mathrm{mg}$; As: $418 \mathrm{mg}$ ) material was sublimed in vacuo at oil bath temperature of $160^{\circ} \mathrm{C}$ and cold finger temperature of $-20^{\circ} \mathrm{C}$. After 2 days, a black solid remained in the sublimation apparatus (for $\mathrm{E}=\mathrm{P}: 508 \mathrm{mg} ; \mathrm{E}=\mathrm{As}: 370 \mathrm{mg}$ ), whereas $300 \mathrm{mg}$ of a white waxy solid or $28 \mathrm{mg}$ of a gray amorphous solid was isolated from the cold finger for $\mathrm{E}=\mathrm{P}$ or As, respectively. The white waxy solid was characterized by ${ }^{31} \mathrm{P}$ NMR spectroscopy well corresponding to those of $\mathrm{P}_{4}$ (Supplementary Fig. 3). The gray solid was characterized by powder X-ray diffraction analysis proving that it is amorphous arsenic (Supplementary Figs. 4 and 5). Furthermore, the solid was identified as gray arsenic by ICP-OES (inductively coupled plasma-optical emission spectrometry, Supplementary Fig. 6).

As the $\mathrm{P}_{4} @ \mathbf{C}$ material retained molecular $\mathrm{P}_{4}$, a standard procedure was used to extract it with common solvents as $n$-hexane, toluene, dichloromethane, and THF. For this reason, $\mathrm{P}_{4} @ \mathrm{C}(100 \mathrm{mg})$ was dispersed in exactly $10 \mathrm{~mL}$ of each of these solvents and stirred for $24 \mathrm{~h}$ in the dark. A ${ }^{31} \mathrm{P}$ NMR spectrum of a defined volume (the same in all cases) of the supernatant was recorded using the same standard $\mathrm{C}_{6} \mathrm{D}_{6}$ capillary with defined

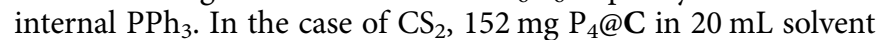
were used (Supplementary Figs. 7-11).

Stability. The stability of $\mathrm{P}_{4} @ \mathbf{C}$ was examined by storing some black solid on the bench in air and under light for 3 weeks. This sample neither ignites spontaneously when brought to air nor reacts with a tissue over time (Supplementary Fig. 17). The solid was then examined with ${ }^{31} \mathrm{P}\left\{{ }^{1} \mathrm{H}\right\}$ MAS NMR. A signal for $\mathrm{P}_{4}$ is only slightly (by $8 \mathrm{ppm}$ ) down-field shifted compared to the inert stored sample. This fact can be attributed to a slightly different interaction in air within the pores (Supplementary Fig. 18). Additionally, solely one sharp signal for a decomposition product at $1.5 \mathrm{ppm}$ is detected. Presumably, it can be attributed to $\mathrm{H}_{3} \mathrm{PO}_{4}$ immobilized within the carbon scaffold, since the signal is in the known range for phosphate derivatives ${ }^{21}$. This may be a result of slow oxidation and hydrolysis to some extent on the surface of the scaffold bound $\mathrm{P}_{4}$. However, it has to be noted that a signal for 

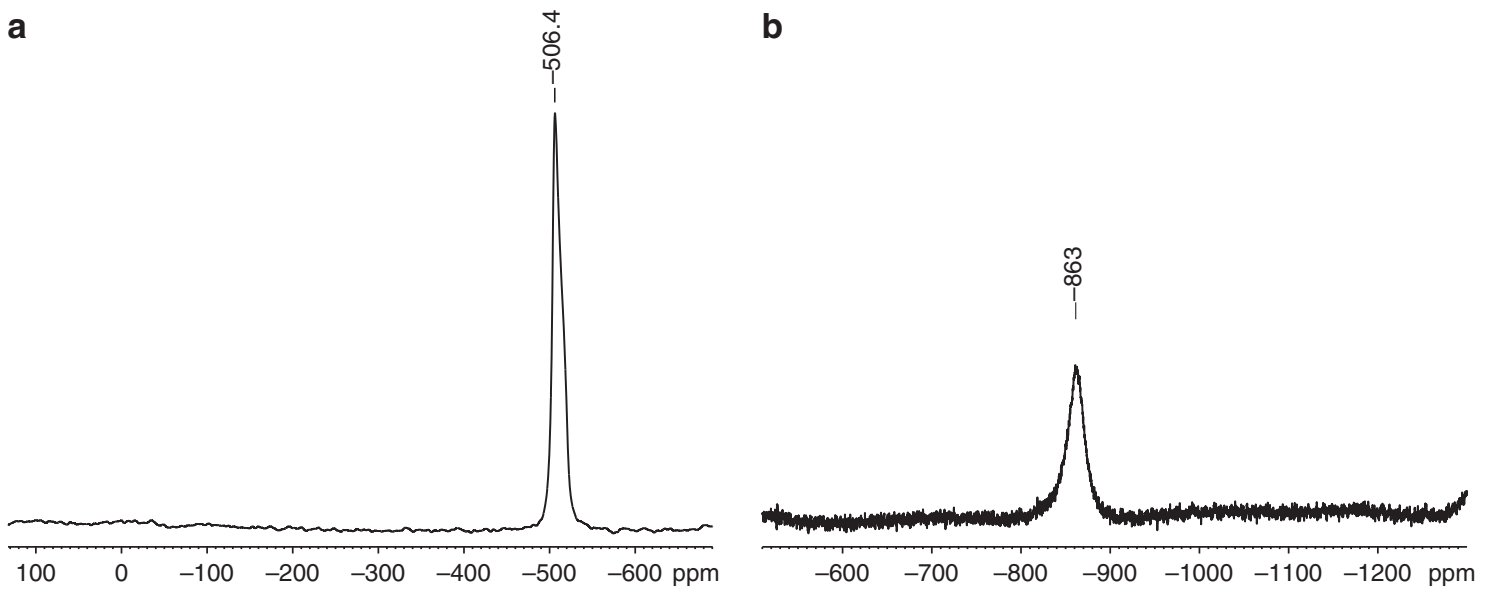

Fig. 1 NMR spectroscopy. a ${ }^{31} P\left\{{ }^{1} H\right\}$ MAS NMR spectrum of $\mathrm{P}_{4} @ \mathbf{C .}$. ${ }^{75} A s N M R$ spectrum of $A s_{4}$ in $C_{2}$ extracted from $A s_{4} @ \mathbf{C}$

white phosphorus can be still detected after storage for 3 weeks in air. Furthermore, $\mathrm{P}_{4} @ \mathbf{C}(88 \mathrm{mg})$ was brought again under nitrogen atmosphere and slurried in $7 \mathrm{~mL} \mathrm{CS}{ }_{2}$ overnight followed by ${ }^{31} \mathrm{P}$ NMR investigation of the colorless supernatant. The same standard $\mathrm{C}_{6} \mathrm{D}_{6}$ capillary with defined internal $\mathrm{PPh}_{3}$ content was used (Supplementary Fig. 19). An intense signal characteristic of free $\mathrm{P}_{4}$ was again monitored. These results clearly prove the stability of $\mathrm{P}_{4} @ \mathbf{C}$ in light and in air to some extent for at least 3 weeks. However, storage in air is not recommended due to a possible decomposition over a long period of time.

In the case of arsenic, no spontaneous ignition of $\mathrm{As}_{4} @ \mathbf{C}$ was observed. The material was exposed to light for several days and stored in air, though in a fume hood due to its unknown toxicity. However, after extraction with $\mathrm{CS}_{2}$, no signal for $\mathrm{As}_{4}$ was monitored by ${ }^{75} \mathrm{As}$ NMR spectroscopy. Consequently, the extracted $\mathrm{As}_{4}$ is likely harmed by slight oxygen and to some extent moisture uptake within the scaffold. Nevertheless, after sublimation for $48 \mathrm{~h}$ at the above-mentioned conditions, resulting gray solid being undoubtedly authenticated by ICP-OES as gray arsenic (Supplementary Figs. 20 and 21).

Recycling. The used storage material $\mathbf{C}$ can be recycled and used again for storage purposes, especially for phosphorus. After washing $\mathrm{E}_{4}$ out of $\mathrm{E}_{4} @ \mathbf{C}$, the regained storage material $\mathbf{C}$ is to be heated for several hours in high vacuum before it can be again loaded with solutions of $\mathrm{E}_{4}$.

\section{Discussion}

For $\mathrm{P}_{4} @ \mathrm{C}$, the decrease of the $\mathrm{P}_{4}$ concentration of the THF supernatant during the synthesis of the loaded material was determined by ${ }^{31} \mathrm{P}$ NMR spectroscopy, indicating a minimum uptake of at least $18 \%$ phosphorus by mass. This result is in accordance with the elemental analysis of $\mathrm{P}_{4} @ \mathbf{C}$ indicating 20\% phosphorus by mass, which is considerably more than for the tetranuclear iron complex described, e.g., by Nitschke with only $3.5 \%$ phosphorus by mass or for the $\mathrm{P}_{4}$-MOF complex by Kawano with $6.9 \%$ phosphorus by mass ${ }^{6,9}$. The solid state ${ }^{31} \mathrm{P}\left\{{ }^{1} \mathrm{H}\right\}$ MAS NMR spectrum of $\mathrm{P}_{4} @ \mathbf{C}$ reveals solely a broad singlet with a chemical shift of $-506.4 \mathrm{ppm}\left(\omega_{1 / 2}=1582 \mathrm{~Hz}\right)$ (Fig. 1a), which is in good agreement with the reported chemical shift of the encapsulated $\mathrm{P}_{4}$ molecule in spherical aggregates $(-506 \mathrm{ppm})^{10}$. The signal is high-field shifted compared to $\mathrm{P}_{4}$ both as a solid $(-462 \mathrm{ppm})$ and a liquid $(-460 \mathrm{ppm})$, due to the interaction with its environment ${ }^{22-25}$. In contrast, the signal is low-field shifted compared to $\mathrm{P}_{4}$ in the gas phase ( $\left.-553 \mathrm{ppm}\right)$ and in solution (e.g., in benzene $-522 \mathrm{ppm})^{23,26}$. For the arsenic compound $\mathrm{As}_{4} @ \mathbf{C}$, no assignable signal can be detected in the solid-state ${ }^{75}$ As MAS NMR spectrum, which can be attributed to the low sensitivity of the quadrupolar nucleus ${ }^{75} \mathrm{As}\left(Q_{\text {spec }}=0.314(6) b=0.314(6) \times 10\right.$ $\left.-28 \mathrm{~m}^{2}\right)^{27}$. However, a broad signal for free $\mathrm{As}_{4}$ can be detected in the ${ }^{75} \mathrm{As}$ NMR spectrum at $-863 \mathrm{ppm}\left(\omega_{1 / 2}=2060 \mathrm{~Hz}\right)$ by extraction of $\mathrm{As}_{4} @ \mathbf{C}$ with $\mathrm{CS}_{2}$ (Fig. 1b). Interestingly, this NMR spectrum was recorded after the storage of the $\mathrm{As}_{4}$ containing material in a glove box in the presence of light for more than 2 weeks. Consequently, $\mathrm{As}_{4} @ \mathbf{C}$ can be seen as light-stable storage material of intact yellow arsenic. The chemical shift is also in good agreement with the reported values $(-892 \mathrm{ppm}$ for toluene/ $\mathrm{CD}_{2} \mathrm{Cl}_{2}$ and $-908 \mathrm{ppm}$ for $\mathrm{THF} / \mathrm{CD}_{2} \mathrm{Cl}_{2}$, respectively) considering the influence of the different solvents ${ }^{10}$.

The powder X-ray diffractograms of $\mathrm{E}_{4} @ \mathrm{C}(\mathrm{E}=\mathrm{P}, \mathrm{As})$ show only two broad peaks arising from the amorphous carbon material and no diffraction pattern of $E_{4}$ units (Fig. 2a). Thus, no crystalline $\mathrm{E}_{4}$ is present in the scaffold, indicating that the arsenic and phosphorus tetrahedra, respectively, are located in the pores $(<5 \mathrm{~nm})$. To clarify the distribution of the $\mathrm{E}_{4}(\mathrm{E}=\mathrm{P}, \mathrm{As})$ molecules, the nitrogen adsorption measurement at liquid nitrogen temperature of $\mathrm{E}_{4} @ \mathbf{C}$ was examined and the DFT (density functional theory)-based pore size distribution was determined (Fig. 2b). As a result of the $\mathrm{P}_{4}$ storage, the specific surface area and the total pore volume of the carbon host decrease by $55 \%$ and 57\%, respectively. Considering the bulk density of $\mathrm{P}_{4}\left(1.82 \mathrm{~g} \mathrm{~cm}^{-3}\right)^{28}$, the maximum amount of $\mathrm{P}_{4}$ in $\mathrm{P}_{4} @ \mathbf{C}$ is approximately $36 \%$. The DFT pore size distribution displays the lack of the ultramicropores $(<0.7 \mathrm{~nm})$ as well as an intense decrease of supermicropores $(0.7<2 \mathrm{~nm})$ (Fig. 2c). Considering a P-P bond length of approx. $2.21 \AA$ and a van der Waals radius of $1.80 \AA$ for a phosphorus atom, the size of the $\mathrm{P}_{4}$ molecules (tetrahedrally shaped sphere with a diameter of about $0.61 \mathrm{~nm}$ ) is similar to the pore size of the carbon host enabling a good fit into the ultramicropores ${ }^{29,30}$. Additionally, the amount of meso pores $(>2 \mathrm{~nm})$ diminishes. These results prove the incorporation of the $\mathrm{P}_{4}$ molecules into the porous activated carbon. For $\mathrm{As}_{4} @ \mathbf{C}$, the specific surface area and the total pore volume decrease by $9 \%$ and $14 \%$, respectively. Considering the bulk density of $\mathrm{As}_{4}(1.97 \mathrm{~g}$ $\left.\mathrm{cm}^{-3}\right)^{28}$, the maximum amount of $\mathrm{As}_{4}$ in $\mathrm{As}_{4} @ \mathbf{C}$ is approximately $10 \%$. With a diameter of about $0.65 \mathrm{~nm}, \mathrm{As}_{4}$ molecules smoothly fit into the carbon scaffold. The thermogravimetric analysis of $\mathrm{As}_{4} @ \mathbf{C}$ shows two steps of a loss of weight. In a first step, until $350{ }^{\circ} \mathrm{C}$, the sample loses approximately $10 \%$ of its weight followed by an additional loss of $10 \%$ until $600{ }^{\circ} \mathrm{C}$ (Fig. 2d). In contrast, the thermogravimetric analysis of solid $\mathrm{P}_{4} @ \mathbf{C}$ shows a loss of weight 
a

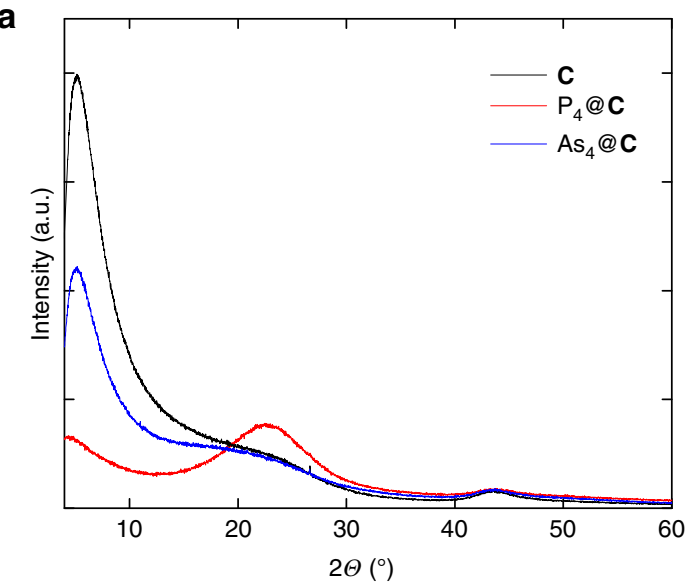

c

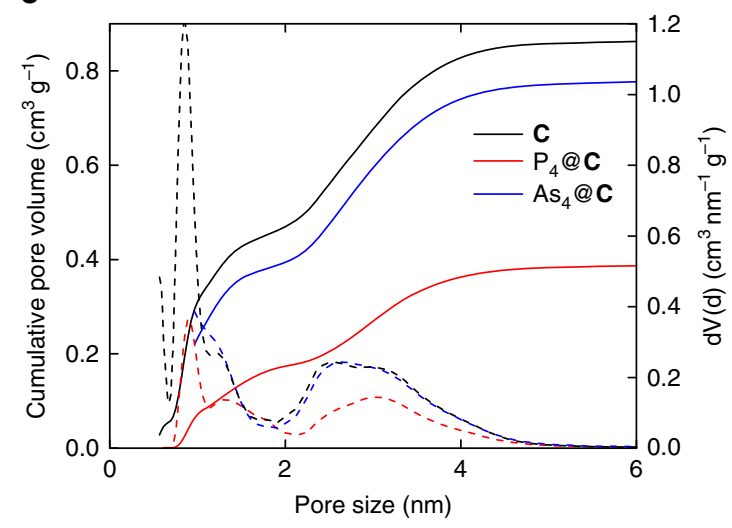

b

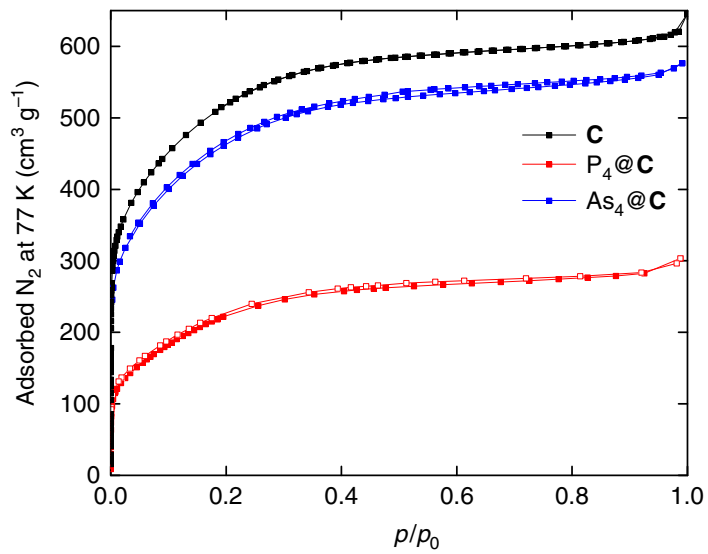

d

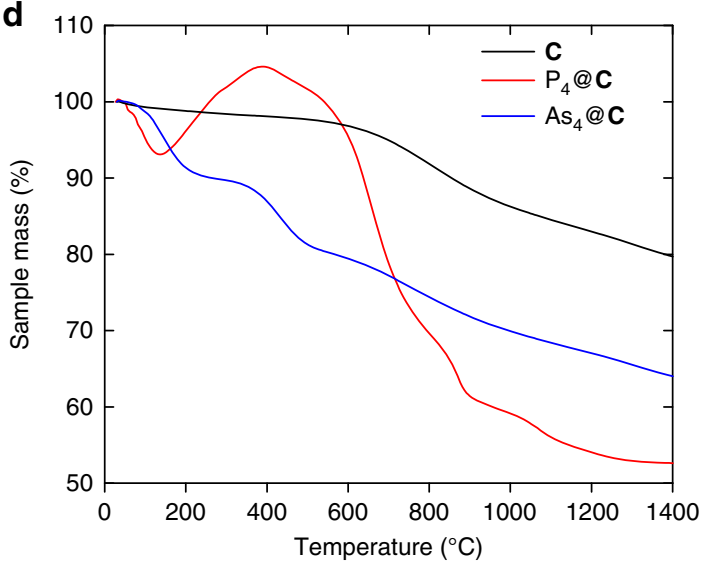

Fig. 2 Comparisons of unloaded carbon material C (black), $\mathrm{P}_{4} @ \mathbf{C}$ (red) and As $\mathrm{s}_{4} @ \mathbf{C}$ (blue). a Powder X-ray diffractograms. b Nitrogen physisorption isotherms at $77 \mathrm{~K}$. c DFT pore size distribution. $\mathbf{d}$ Thermogravimetric curve

of about $10 \%$ until $180^{\circ} \mathrm{C}$ followed by an unexpected, but reproducible increase of the sample mass by $10 \%$ (Fig. $2 \mathrm{~d}$ ). Between 400 and $800^{\circ} \mathrm{C}$, a loss of weight of $32 \%$ is again detected resulting from released phosphorus.

Additionally, the suitability of $\mathrm{E}_{4} @ \mathbf{C}$ for the preparative release of intact white phosphorus and yellow arsenic was investigated. By sublimation, a white waxy solid of $\mathrm{P}_{4}$ can be isolated within two days at $160{ }^{\circ} \mathrm{C}$ in vacuum. The ${ }^{31} \mathrm{P}$ NMR spectrum of this solid, dissolved in benzene- $d_{6}$ (singlet at $-519.5 \mathrm{ppm}$ ), proves unambiguously that the $\mathrm{P}_{4}$ tetrahedra are still intact. The so obtained amount of phosphorus ( $36 \%$ by mass) indicates a maximum amount for the uptake of the porous carbon material and is in very good agreement with the calculated value of incorporated white phosphorus. The analogous sublimation with $\mathrm{As}_{4} @ \mathrm{C}$ leads to the release of $\mathrm{As}_{4}$ and the isolation of at least 7\% arsenic by mass. Due to the instability of yellow arsenic under light exposure, only a gray amorphous solid was isolated, which can be attributed to gray arsenic by ICP-OES. Furthermore, the extraction of $\mathrm{P}_{4}$ by different common solvents such as $\mathrm{CS}_{2}, n$ hexane, toluene, dichloromethane and THF was explored. A standard procedure for these solvents reveals that $17-21 \% \mathrm{P}_{4}$ by mass can be extracted. In the case of yellow arsenic, extraction with common solvents as for instance $n$-pentane and toluene showed experimentally a release of about $5-10 \%$ arsenic by mass.

Additionally, we were interested in the use of $\mathrm{E}_{4} @ \mathbf{C}$ for subsequent chemical reactions because activated carbon as an inert material should not harm chemical reactions by unintended contaminations in the way different metal ions do. Compared to known storage materials, which are based on multi-component systems containing metal ions, our system solely consists of an a

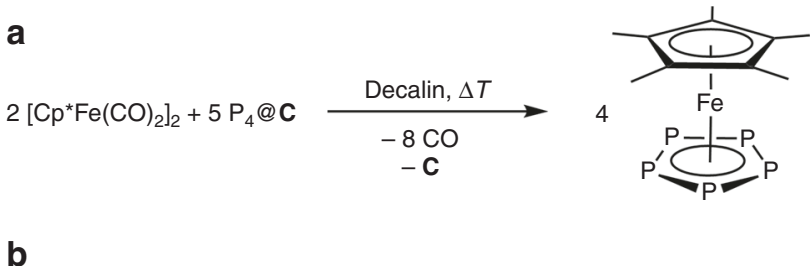

$\left[\mathrm{Cp}{ }^{\mathrm{BIG}} \mathrm{Fe}(\mathrm{CO})_{2}\right]_{2}+\mathrm{E}_{4} @ \mathbf{C} \quad \stackrel{\text { Toluene, r.t. }}{-\mathbf{C}}$

$$
\begin{aligned}
& {[\mathrm{Fe}]} \\
& {[\mathrm{Fe}]=\left[\mathrm{Cp}^{\mathrm{BIG}} \mathrm{Fe}(\mathrm{CO})_{2}\right]}
\end{aligned}
$$

Fig. 3 Reactivity studies. a Synthesis of $\left[C p^{\star} \mathrm{Fe}\left(\eta^{5}-\mathrm{P}_{5}\right)\right]$. $\mathbf{b}$ Synthesis of $\left[\left(\mathrm{Cp}^{\mathrm{BIG}} \mathrm{Fe}(\mathrm{CO})_{2}\right)_{2}\left(\mu, \eta^{1: 1}-\mathrm{E}_{4}\right)\right](\mathrm{E}=\mathrm{P}, \mathrm{As})$

inert carbon host thus not resulting in any competitive reactions. That way, we succeeded in the synthesis of the reported compounds starting from $\mathrm{E}_{4} @ \mathrm{C}(\mathrm{E}=\mathrm{P}, \mathrm{As})$. For example, the reaction of $\mathrm{P}_{4} @ \mathbf{C}$ with $\left[\mathrm{Cp}^{\star} \mathrm{Fe}(\mathrm{CO})_{2}\right]_{2}$ in boiling decalin leads to the formation of the desired pentamethylcyclopentadienylpentaphosphaferrocene $\left[\mathrm{Cp}{ }^{*} \mathrm{Fe}\left(\eta^{5}-\mathrm{P}_{5}\right)\right]$ (Fig. 3a) $)^{31}$. Additionally, $\mathrm{P}_{4} @ \mathrm{C}$ was reacted with $\left[\mathrm{Cp}^{\mathrm{BIG}} \mathrm{Fe}(\mathrm{CO})_{2}\right]_{2} \quad\left(\mathrm{Cp}^{\mathrm{BIG}}=\mathrm{C}_{5}(4-\right.$ $\left.\left.n \mathrm{BuC}_{6} \mathrm{H}_{4}\right)_{5}\right)$ at room temperature, analogously to the reported procedure ${ }^{32}$ starting from dissolved $\mathrm{P}_{4}$, resulting in the quantitative synthesis of the $\mathrm{P}_{4}$ butterfly complex $\left[\left(\mathrm{Cp}^{\mathrm{BIG}} \mathrm{Fe}(\mathrm{CO})_{2}\right)_{2}(\mu\right.$, $\left.\left.\eta^{1: 1}-\mathrm{P}_{4}\right)\right]$ (Fig. 3b). The analogous reaction was also observed for $\mathrm{As}_{4} @ \mathbf{C}$. Therefore, $\mathrm{E}_{4} @ \mathbf{C}$ has been shown to be a convenient source of white phosphorus and yellow arsenic for subsequent reactions. Because $\mathrm{As}_{4} @ \mathbf{C}$ can also be used to deliver yellow 
arsenic at low temperatures for chemical syntheses, it becomes a useful synthetic tool and opens broad perspectives for its application.

Moreover, $\mathrm{P}_{4} @ \mathbf{C}$ can be stored for at least four weeks in light and in air, without the black solid igniting spontaneously in air. After the storage of $\mathrm{P}_{4} @ \mathbf{C}$ for three weeks in air on a bench, the solid-state ${ }^{31} \mathrm{P}\left\{{ }^{1} \mathrm{H}\right\}$ MAS NMR spectrum still reveals one broad singlet with a chemical shift of $-498.4 \mathrm{ppm}$, which can be attributed to white phosphorus $\mathrm{P}_{4}$. This signal is only slightly shifted compared to the signal of $\mathrm{P}_{4} @ \mathbf{C}$ stored in a glove box and is still in good agreement with the reported chemical shifts of $\mathrm{P}_{4}$. However, solely one additional very weak signal at $1.5 \mathrm{ppm}$ was detected resulting presumably from traces of the oxidation of solid $\mathrm{P}_{4}$ and subsequent hydrolysis to some extent. Nevertheless, $\mathrm{P}_{4}$ can be still extracted with $\mathrm{CS}_{2}$ monitored by the ${ }^{31} \mathrm{P}$ NMR spectroscopy and no decomposition product of $\mathrm{P}_{4}$ was observed by the solution ${ }^{31} \mathrm{P}$ NMR spectroscopy in contrast to the solidstate NMR spectroscopy. Principally, As $\mathrm{s}_{4} @ \mathbf{C}$ can also be stored in light and in air, but the storage in air is not recommended due to its unknown toxicity. The stability of the $\mathrm{E}_{4}$ tetrahedra in the porous material might be attributed to its interaction within the pores of the carbon material since the tetrahedral structure and size of the $\mathrm{E}_{4}$ molecules match nearly perfectly the size of the pores and the cavities of the carbon scaffold, respectively. Anyhow, long-time storage of $\mathrm{E}_{4} @ \mathrm{C}$ in air should be avoided due to a possible slow decomposition process.

In summary, we have shown the facile storage and release of yellow arsenic and white phosphorus in an inert and low-cost activated carbon-based porous material. Because of the stabilization of these metastable compounds in a porous framework, we succeeded in synthesizing a light-stable, storable and conveyable $\mathrm{P}_{4}$ and $\mathrm{As}_{4}$ source. This allows for example unproblematic shipping, especially of white phosphorus, which is hindered by law for small batches, and renders possible the shipping of yellow arsenic as a stabilized material. Additionally, these sources can be used directly for chemical reactions. As a result, new applications for phosphorus and arsenic chemistry are opened up for academia and industry. That way, the $\mathrm{As}_{4}$ containing material is especially regarded as a suitable arsenic source with a high potential, e.g., for new approaches in arsenic chemistry and, for instance, in semiconductor technologies e.g., for chemical vapor deposition (CVD) processes. Because of the multiple use of the carbon-based material for storage and release, it becomes an extremely useful and low-cost solid for these purposes. The uploading of other unstable molecules might create important perspectives thus representing a topic of future investigations.

\section{Methods}

General. All manipulations were performed under an atmosphere of dry nitrogen and under exclusion of oxygen and moisture using standard Schlenk and glove box techniques. All solvents were dried using conventional techniques, degassed and saturated with nitrogen prior to use.

Activation of porous carbon material. The porous carbon material (C, commercially available Norit DLC Super 50 of the Cabot Norit Nederland BV) was activated in vacuo at $140{ }^{\circ} \mathrm{C}$ before utilization.

Characterization. NMR spectroscopy: ${ }^{1} \mathrm{H},{ }^{31} \mathrm{P}\left\{{ }^{1} \mathrm{H}\right\}$ and ${ }^{31} \mathrm{P}$ NMR spectra were recorded on a Bruker Avance $400\left({ }^{1} \mathrm{H}: 400.130 \mathrm{MHz},{ }^{31} \mathrm{P}: 161.976 \mathrm{MHz}\right)$ or on a Bruker Avance $300\left({ }^{1} \mathrm{H}: 300.132 \mathrm{MHz},{ }^{31} \mathrm{P}: 121.495 \mathrm{MHz}\right)$ spectrometer. The chemical shifts are reported in ppm relative to external TMS $\left({ }^{1} \mathrm{H}\right)$ and $85 \% \mathrm{H}_{3} \mathrm{PO}_{4}$ $\left.{ }^{(31} \mathrm{P}\right)$. The ${ }^{75} \mathrm{As}$ NMR spectra were recorded on a Bruker Avance III HD 600 $(600.13 \mathrm{MHz})$ spectrometer, equipped with a $5 \mathrm{~mm}$ TBI-probehead $\left({ }^{1} \mathrm{H}, \mathrm{X},{ }^{19} \mathrm{~F}\right)$ and $\left({ }^{1} \mathrm{H}, \mathrm{X},{ }^{31} \mathrm{P}\right)$ with $\mathrm{Z}$-gradient, respectively, and externally referenced to $\mathrm{Na}$ $\left[\mathrm{AsF}_{6}\right]$. The ${ }^{31} \mathrm{P}\left\{{ }^{1} \mathrm{H}\right\}$ MAS NMR spectra were recorded on a Bruker Avance 300 $\mathrm{MHz}$ device and referenced to external $\mathrm{NaH}_{2} \mathrm{PO}_{4}(2.3 \mathrm{ppm})$.

IR spectroscopy: The IR spectra were measured on a VARIAN FTS-800 FT-IR spectrometer.
Raman spectroscopy: The Raman spectra were recorded on a Thermo Fisher Scientific DXR-Smart-Raman spectrometer (excitation laser $532 \mathrm{~nm}$; Supplementary Fig. 22).

EPR spectroscopy: The X-Band EPS spectra were recorded on a Magnettech MiniScope MS400 spectrometer with $9 \mathrm{GHz}$ microwave frequency (Supplementary Fig. 23).

Elemental analysis: The elemental analysis was performed by the Catalysis Research Center of the Technical University of Munich. Phosphorus was thereby photometrically determined by the P-vanadate method. C, $\mathrm{H}$ and $\mathrm{N}$ were determined by combustion analysis. The values are seen as benchmarks since the sample was not totally stable during weighing.

Powder X-ray diffraction analysis: Powder X-ray data were collected using a X'Pert Pro diffractometer from PANalytical with $\mathrm{Cu}_{K \alpha 1}$ radiation $(\lambda=1.5406 \AA)$ in reflection mode from $4^{\circ}$ to $60^{\circ} 2 \theta$.

Physisorption and DFT pore size distribution: Prior to porosity analysis, porous samples were degassed under vacuum at room temperature for $24 \mathrm{~h}$. Nitrogen physisorption measurements at $-196^{\circ} \mathrm{C}$ were carried out on a Quadrasorb apparatus (Quantachrome Instruments) and an Autosorb 1 C (Quantachrome Instruments) for low-pressure experiments. Specific surface areas were calculated using the micropore BET assistant of the ASiQwin 3.01 software from Quantachrome to find the optimum $P / P_{0}$. Total pore volumes were determined from the amount of adsorbed nitrogen at $0.95 P / P_{0}$. Pore size distributions (PSDs) were calculated using the quenched solid density functional theory method for carbon (slit/cylindrical pores, adsorption branch). Micropore volumes are estimated from the cumulative pore volumes at a diameter of $2 \mathrm{~nm}$.

Thermogravimetric analysis: TG-DTA under argon atmosphere was measured with a Netzsch STA 409 PC/PG. An empty corundum crucible was used as a reference and the heating ramp was $1 \mathrm{~K} \mathrm{~min}^{-1}$.

Syntheses. Synthesis of $\mathrm{P}_{4} @$ C: A solution of $\mathrm{P}_{4}(595 \mathrm{mg}, 4.80 \mathrm{mmol})$ in $40 \mathrm{~mL}$ THF was added to activated C ( $975 \mathrm{mg})$ and stirred for $17 \mathrm{~h}$ in the dark. Afterward, the black slurry was centrifuged and the supernatant was decanted. The resulting black solid was washed with $n$-pentane $(2 \times 10 \mathrm{~mL})$ and dried in vacuo. Yield: 1.46 g. For the determination of the decrease of white phosphorus, ${ }^{31} \mathrm{P}$ NMR spectra of the supernatant before and after addition of the solution to the activated carbon were recorded (Supplementary Figs. 1 and 2). Hereby, defined sample volumes were used and a standard $\mathrm{C}_{6} \mathrm{D}_{6}$ capillary with defined amount of $\mathrm{PPh}_{3}$ as internal standard was utilized. ${ }^{31} \mathrm{P}\left\{{ }^{1} \mathrm{H}\right\}$ MAS NMR $(121 \mathrm{MHz}, 300 \mathrm{~K}): \delta[\mathrm{ppm}]=-506.4(\mathrm{~s}$, br, $\omega_{1 / 2}=1582 \mathrm{~Hz}, \mathrm{P}_{4}$ ); elemental analysis (\%): found: C, 72.66; H, 0.93; N, 0.18; P, 20.45 .

Synthesis of yellow arsenic: Solutions of yellow arsenic were prepared according to literature procedures ${ }^{19,33}$.

Synthesis of $\mathrm{As}_{4} @ \mathbf{C}$ : A freshly prepared solution of $\mathrm{As}_{4}$ (ca. $150 \mathrm{mg}$, starting from $\sim 6-8 \mathrm{~g}$ gray arsenic) in $250 \mathrm{~mL}$ THF was filtered over diatomaceous earth and added to activated C $(1.0 \mathrm{~g})$. The black suspension was then stirred for $\sim 17 \mathrm{~h}$ in the dark. Subsequently, the slurry was centrifuged and the supernatant was decanted. Afterward, the black solid was washed with $n$-pentane $(1 \times 30 \mathrm{~mL})$ and dried in vacuo. Yield: $1.1 \mathrm{~g}$.

Synthesis of $\left[\mathrm{Cp} \mathrm{p}^{*} \mathrm{Fe}\left(\eta^{5}-\mathrm{P}_{5}\right)\right]: \mathrm{P}_{4} @ \mathrm{C}(661 \mathrm{mg})$ and $\left[\mathrm{Cp}^{*} \mathrm{Fe}(\mathrm{CO})_{2}\right]_{2}(50 \mathrm{mg}, 0.10$ mmol) were refluxed in boiling decalin $(30-40 \mathrm{~mL})$ for $2 \mathrm{~h}$. Subsequently, the solvent was removed resulting in a gray black solid. The latter was slurried in dichloromethane and filtered over diatomaceous earth and then over $\mathrm{SiO}_{2}$. The green filtrate was brought to dryness resulting in a dark green solid. The NMR chemical shifts (NMR spectra: Supplementary Figs. 12 and 13) are in very good agreement with the literature values ${ }^{31}$. Yield: $5 \mathrm{mg}(0.014 \mathrm{mmol}, 7 \%) .{ }^{1} \mathrm{H}$ NMR $\left(\mathrm{CD}_{2} \mathrm{Cl}_{2}, 400 \mathrm{MHz}, 300 \mathrm{~K}\right): \delta[\mathrm{ppm}]=1.43\left(\mathrm{~s}, 15 \mathrm{H}, \mathrm{C}_{5}\left(\mathrm{CH}_{3}\right)_{5}\right) ;{ }^{31} \mathrm{P}\left\{{ }^{1} \mathrm{H}\right\} \mathrm{NMR}$ $\left(\mathrm{CD}_{2} \mathrm{Cl}_{2}, 161 \mathrm{MHz}, 300 \mathrm{~K}\right): \delta[\mathrm{ppm}]=152.2\left(\mathrm{~s}, P_{5}\right) ;{ }^{31} \mathrm{P} \mathrm{NMR}\left(\mathrm{CD}_{2} \mathrm{Cl}_{2}, 161 \mathrm{MHz}\right.$ $300 \mathrm{~K}): \delta[\mathrm{ppm}]=152.2\left(\mathrm{~s}, P_{5}\right)$

Synthesis of $\left[\left\{\mathrm{Cp}^{\mathrm{BIG}} \mathrm{Fe}(\mathrm{CO})_{2}\right\}_{2}\left(\mu, \eta^{1: 1}-\mathrm{P}_{4}\right)\right]$ : A green solution of $\left[\mathrm{Cp}^{\mathrm{BIG}} \mathrm{Fe}\right.$ $\left.(\mathrm{CO})_{2}\right]_{2}\left(\mathrm{Cp}^{\mathrm{BIG}}=\mathrm{C}_{5}\left(4-n \mathrm{BuC}_{6} \mathrm{H}_{4}\right)_{5}\right)(100 \mathrm{mg}, 0.06 \mathrm{mmol})$ in toluene $(10 \mathrm{~mL})$ was added to solid $\mathrm{P}_{4} @ \mathbf{C}(40 \mathrm{mg})$. Immediately, the supernatant of the black suspension turned orange. The suspension was brought to dryness and slurried in dichloromethane. Then, the slurry was filtered over diatomaceous earth. The orange filtrate was brought to dryness. The analytical data are in very good agreement with the reported values (NMR spectra: Supplementary Figs. 14 and 15) 32. Yield: $98 \mathrm{mg}\left(0.054 \mathrm{mmol}, 91 \%\right.$ based on $\left.\left[\mathrm{Cp}^{\mathrm{BIG} F e}(\mathrm{CO})_{2}\right]_{2}\right)$. ${ }^{1} \mathrm{H}$ NMR $\left(\mathrm{C}_{6} \mathrm{D}_{6}\right.$, $400 \mathrm{MHz}, 300 \mathrm{~K}): \delta[\mathrm{ppm}]=0.80\left(\mathrm{t},{ }^{3} J(\mathrm{H}, \mathrm{H})=7.3 \mathrm{~Hz}, 30 \mathrm{H}, \mathrm{CH}_{3}\right), 1.16(\mathrm{~m}, 20 \mathrm{H}$, $\left.\mathrm{CH}_{2}\right), 1.35\left(\mathrm{~m}, 20 \mathrm{H}, \mathrm{CH}_{2}\right), 2.29\left(\mathrm{t},{ }^{3} \mathrm{~J}(\mathrm{H}, \mathrm{H})=7.8 \mathrm{~Hz}, 20 \mathrm{H}, \mathrm{CH}_{2}\right), 6.72\left(\mathrm{~d},{ }^{3} \mathrm{~J}(\mathrm{H}, \mathrm{H})\right.$ $\left.=8.0 \mathrm{~Hz}, 20 \mathrm{H}, \mathrm{C}_{6} \mathrm{H}_{4}\right), 7.32\left(\mathrm{~d},{ }^{3} \mathrm{~J}(\mathrm{H}, \mathrm{H})=8.0 \mathrm{~Hz}, 20 \mathrm{H}, \mathrm{C}_{6} \mathrm{H}_{4}\right) ;{ }^{31} \mathrm{P}$ NMR $\left(\mathrm{C}_{6} \mathrm{D}_{6}\right.$, $161 \mathrm{MHz}, 300 \mathrm{~K}): \delta[\mathrm{ppm}]=-54.1\left(\mathrm{t},{ }^{1} J(\mathrm{P}, \mathrm{P})=187 \mathrm{~Hz}, 2 \mathrm{P}, \mathrm{Fe}-P-\mathrm{P}\right),-317.2\left(\mathrm{t},{ }^{1} J\right.$ $(\mathrm{P}, \mathrm{P})=187 \mathrm{~Hz}, 2 \mathrm{P}, \mathrm{Fe}-\mathrm{P}-\mathrm{P}) ;{ }^{31} \mathrm{P}\left\{{ }^{1} \mathrm{H}\right\}$ NMR $\left(\mathrm{C}_{6} \mathrm{D}_{6}, 161 \mathrm{MHz}, 300 \mathrm{~K}\right): \delta[\mathrm{ppm}]=$ $-54.1\left(\mathrm{t},{ }^{1} J(\mathrm{P}, \mathrm{P})=187 \mathrm{~Hz}, 2 \mathrm{P}, \mathrm{Fe}-P-\mathrm{P}\right),-317.2\left(\mathrm{t},{ }^{1} J(\mathrm{P}, \mathrm{P})=187 \mathrm{~Hz}, 2 \mathrm{P}, \mathrm{Fe}-\mathrm{P}-P\right)$; IR (toluene): $\tilde{v}\left[\mathrm{~cm}^{-1}\right]=2002(\mathrm{~s}), 1955(\mathrm{~s})$.

Synthesis of $\left[\left\{\mathrm{Cp}^{\mathrm{BIG}} \mathrm{Fe}(\mathrm{CO})_{2}\right\}_{2}\left(\mu, \eta^{1: 1}-\mathrm{As}_{4}\right)\right]$ : A green solution of $\left[\mathrm{Cp}^{\mathrm{BIG}} \mathrm{Fe}\right.$ $\left.(\mathrm{CO})_{2}\right]_{2}\left(\mathrm{Cp}^{\mathrm{BIG}}=\eta^{5}-\mathrm{C}_{5}\left(4-n \mathrm{BuC}_{6} \mathrm{H}_{4}\right)_{5}\right)(100 \mathrm{mg}, 0.06 \mathrm{mmol})$ in toluene $(10 \mathrm{~mL})$ was added to solid As $@$ @ $(400 \mathrm{mg})$. Thereby, the supernatant of the black suspension turned red-orange. The suspension was brought to dryness and slurried in dichloromethane. Then, the slurry was filtered over diatomaceous earth. The red-orange filtrate was brought to dryness. The analytical data are in very good agreement with the reported values (NMR spectra: Supplementary Fig. 16) ${ }^{32}$. Yield: $93 \mathrm{mg}\left(0.047 \mathrm{mmol}, 78 \%\right.$ based on $\left.\left[\mathrm{Cp}^{\mathrm{BIG}} \mathrm{Fe}(\mathrm{CO})_{2}\right]_{2}\right) .{ }^{1} \mathrm{H} \mathrm{NMR}\left(\mathrm{C}_{6} \mathrm{D}_{6}, 400 \mathrm{MHz}\right.$, 
$300 \mathrm{~K}): \delta[\mathrm{ppm}]=0.80\left(\mathrm{t},{ }^{3} \mathrm{~J}(\mathrm{H}, \mathrm{H})=7.2 \mathrm{~Hz}, 30 \mathrm{H}, \mathrm{CH}_{3}\right), 1.15\left(\mathrm{~m}, 20 \mathrm{H}, \mathrm{CH}_{2}\right), 1.33$ $\left(\mathrm{m}, 20 \mathrm{H}, \mathrm{CH}_{2}\right), 2.27\left(\mathrm{t},{ }^{3} \mathrm{~J}(\mathrm{H}, \mathrm{H})=7.8 \mathrm{~Hz}, 20 \mathrm{H}, \mathrm{CH}_{2}\right), 6.71\left(\mathrm{~d},{ }^{3} \mathrm{~J}(\mathrm{H}, \mathrm{H})=8.0 \mathrm{~Hz}, 20\right.$ $\left.\mathrm{H}, \mathrm{C}_{6} \mathrm{H}_{4}\right), 7.32\left(\mathrm{~d},{ }^{3} \mathrm{~J}(\mathrm{H}, \mathrm{H})=8.0 \mathrm{~Hz}, 20 \mathrm{H}, \mathrm{C}_{6} \mathrm{H}_{4}\right)$; IR (toluene): $\tilde{v}\left[\mathrm{~cm}^{-1}\right]=1993(\mathrm{~s})$, 1947 (s).

Data availability. The data that support the findings of this study are available from the corresponding author on reasonable request; see author contributions for specific data sets.

Received: 11 September 2017 Accepted: 20 December 2017.

Published online: $\mathrm{xx}$ xxx 2018

\section{References}

1. Krafft, F. Phosphorus. From elemental light to chemical element. Angew. Chem. Int. Ed. Engl. 8, 660-671 (1969).

2. Cossairt, B. M., Piro, N. A. \& Cummins, C. C. Early-transition-metal-mediated activation and transformation of white phosphorus. Chem. Rev. 110, 4164-4177 (2010).

3. Caporali, M., Gonsalvi, L., Rossin, A. \& Peruzzini, M. $\mathrm{P}_{4}$ activation by latetransition metal complexes. Chem. Rev. 110, 4178-4235 (2010).

4. Scheer, M., Balázs, G. \& Seitz, A. $\mathrm{P}_{4}$ activation by main group elements and compounds. Chem. Rev. 110, 4236-4256 (2010).

5. Giffin, N. A. \& Masuda, J. D. Reactivity of white phosphorus with compounds of the p-block. Coord. Chem. Rev. 255, 1342-1359 (2011).

6. Mal, P., Breiner, B., Rissanen, K. \& Nitschke, J. R. White phosphorus is airstable within a self-assembled tetrahedral capsule. Science 324, 1697-1699 (2009).

7. Yang, D. et al. Air- and light-stable $\mathrm{P}_{4}$ and $\mathrm{As}_{4}$ within an anion-coordinationbased tetrahedral cage. J. Am. Chem. Soc. 139, 5946-5951 (2017).

8. Yang, D. et al. Correction to "air- and light-stable $\mathrm{P}_{4}$ and $\mathrm{As}_{4}$ within an anioncoordination-based tetrahedral cage". J. Am. Chem. Soc. 139, 7130-7130 (2017).

9. Choi, W., Ohtsu, H., Matsushita, Y. \& Kawano, M. Safe $\mathrm{P}_{4}$ reagent in a reusable porous coordination network. Dalton Trans. 45, 6357-6360 (2016).

10. Schwarzmaier, C. et al. Stabilization of tetrahedral $\mathrm{P}_{4}$ and $\mathrm{As}_{4}$ molecules as guests in polymeric and spherical environments. Angew. Chem. Int. Ed. 52, 10896-10899 (2013)

11. Krossing, I. $\mathrm{Ag}\left(\mathrm{P}_{4}\right)_{2}{ }^{+}$: the first homoleptic metal-phosphorus cation. J. Am. Chem. Soc. 123, 4603-4604 (2001)

12. Forfar, L. C. et al. White phosphorus as a ligand for the coinage metals. Chem. Commun. 48, 1970-1972 (2012).

13. Schwarzmaier, C., Sierka, M. \& Scheer, M. Intact $\mathrm{As}_{4}$ tetrahedra coordinated side-on to metal cations. Angew. Chem. Int. Ed. 52, 858-861 (2013).

14. Schwarzmaier, C., Timoshkin, A. Y. \& Scheer, M. An end-on-coordinated As tetrahedron. Angew. Chem. Int. Ed. 52, 7600-7603 (2013).

15. Spitzer, F. et al. Fixation and release of intact $\mathrm{E}_{4}$ tetrahedra $(\mathrm{E}=\mathrm{P}, \mathrm{As})$. Angew. Chem. Int. Ed. 54, 4392-4396 (2015).

16. Heinl, S., Reisinger, S., Schwarzmaier, C., Bodensteiner, M. \& Scheer, M. Selective functionalization of $\mathrm{P}_{4}$ by metal-mediated C-P bond formation. Angew. Chem. Int. Ed. 53, 7639-7642 (2014).

17. Heinl, S., Balázs, G., Stauber, A. \& Scheer, M. Cp ${ }^{\mathrm{PEt}}{ }_{2} \mathrm{As}_{4}$ - an organicsubstituted As 4 butterfly compound. Angew. Chem. Int. Ed. 55, 15524-15527 (2016).

18. Bettendorff, A. Allotropische zustände des arsens. Justus. Liebigs. Ann. Chem. 144, 110-114 (1867)

19. Erdmann, H. \& Unruh, M. V. VI. Über gelbes arsen. Z. Anorg. Chem. 32 437-452 (1902).

20. Spinney, H. A., Piro, N. A. \& Cummins, C. C. Triple-bond reactivity of an AsP complex intermediate: synthesis stemming from molecular arsenic, As 4 . J. Am. Chem. Soc. 131, 16233-16243 (2009).

21. Mudrakovskii, I. L., Shmachkova, V. P., Kotsarenko, N. S. \& Mastikhin, V. M. ${ }^{31} \mathrm{P} \mathrm{nmr}$ study of I-IV group polycrystalline phosphates. J. Phys. Chem. Solids 47, 335-339 (1986).

22. Siebert, H., Eints, J. \& Fluck, E. Kernresonanzspektrum und Struktur des Trisilylphosphins. Z. Nat. B 23, 1006 (1968).

23. Heckmann, G. \& Fluck, E. ${ }^{31}$ P-Kernresonanzdaten von weißem phosphor und Lösungen des weißen phosphors. Z. Nat. B 24, 1092-1094 (1969).

24. Oschatz, M. et al. in Annual Reports on NMR Spectroscopy Vol. 87 (ed. Webb Graham, A.) 237-318 (Academic Press, Oxford, 2016).

25. Borchardt, L., Oschatz, M., Paasch, S., Kaskel, S. \& Brunner, E. Interaction of electrolyte molecules with carbon materials of well-defined porosity: characterization by solid-state NMR spectroscopy. Phys. Chem. Chem. Phys. 15, 15177-15184 (2013).

26. Heckmann, G. \& Fluck, E. ${ }^{31}$ P nuclear magnetic resonance chemical shifts of elemental phosphorus in the gas phase. Mol. Phys. 23, 175-183 (1972).

27. Effenberger, B. et al. Determination of the spectroscopic quadrupole moments of ${ }_{33}{ }^{75} \mathrm{As}$ and ${ }_{29}{ }^{63} \mathrm{Cu}$. Z. Phys. A 309, 77-81 (1982).

28. Schenk, P. W. in Handbook of Preparative Inorganic Chemistry 2nd edn (ed. Brauer, G.) 591-629 (Academic Press, New York, 1963).

29. Maxwell, L. R., Hendricks, S. B. \& Mosley, V. M. Electron diffraction by gases. J. Chem. Phys. 3, 699-709 (1935).

30. Bondi, A. van der Waals volumes and radii. J. Chem. Phys. 68, 441-451 (1964).

31. Scherer, O. J. \& Brück, T. [( $\left.\left.\eta^{5}-\mathrm{P}_{5}\right) \mathrm{Fe}\left(\eta^{5}-\mathrm{C}_{5} \mathrm{Me}_{5}\right)\right]$, a pentaphosphaferrocene derivative. Angew. Chem. Int. Ed. Engl. 26, 59 (1987).

32. Heinl, S. \& Scheer, M. Activation of group 15 based cage compounds by $\left[\mathrm{Cp}^{\mathrm{BIG}} \mathrm{Fe}(\mathrm{CO})_{2}\right]$ radicals. Chem. Sci. 5, 3221-3225 (2014).

33. Scherer, O. J., Sitzmann, H. \& Wolmershäuser, G. $\left(\mathrm{E}_{2}\right)_{2}$-Einheiten $(\mathrm{E}=\mathrm{P}, \mathrm{As})$ als clusterbausteine. J. Organomet. Chem. 309, 77-86 (1986).

\section{Acknowledgements}

This work was supported by the Deutsche Forschungsgemeinschaft (DFG). A.E.S. is grateful for a PhD fellowship of the Fonds der Chemischen Industrie. The results are also part of the doctoral thesis of A.E.S., University of Regensburg, 2017. D. Fiedler (powder X-ray diffraction analysis of sublimed gray solid), J. Rewitzer (ICP-OES measurements), F. Hastreiter (measurement of the ${ }^{75}$ As NMR spectra), the Catalysis Research Center of the Technical University of Munich (elemental analysis) and M. Modl (supply of $\left.\left[\mathrm{CP}^{\mathrm{BIG}} \mathrm{Fe}(\mathrm{CO})_{2}\right]_{2}\right)$ are thankfully acknowledged.

\section{Author contributions}

Syntheses and characterizations of $\mathrm{E}_{4} @ \mathrm{C}$ were performed by A.E.S., except the powder $\mathrm{X}$ ray diffraction analyses, thermogravimetric analyses as well as the investigations of the nitrogen adsorption measurement at liquid nitrogen temperature and the DFT pore size distribution of $\mathrm{E}_{4} @ \mathbf{C}$ (F.H.). ${ }^{31} \mathrm{P}\left\{{ }^{1} \mathrm{H}\right\}$ MAS NMR spectra were recorded by W.K. Experiments on the release of $\mathrm{E}_{4}$, reactivity studies of $\mathrm{E}_{4} @ \mathbf{C}$, and the studies on the air stability of $\mathrm{E}_{4} @ \mathbf{C}$ were performed by A.E.S. Figures and schemes were made by A.E.S., except the figures of the powder X-ray diffraction analyses, thermogravimetric analyses as well as the investigations of the nitrogen adsorption measurement at liquid nitrogen temperature and the DFT pore size distribution (F.H.). S.K. and M.S. originated the central idea, supervised the work, analyzed the data, and A.E.S. and M.S. wrote the manuscript with contributions from all the co-authors.

\section{Additional information}

Supplementary Information accompanies this paper at https://doi.org/10.1038/s41467017-02735-2.

Competing interests: This publication concerns the patent: EP 17163405.8 from 28.03.2017 filed by A.E.S., F.H., S.K. and M.S. The remaining author declares no competing financial interests.

Reprints and permission information is available online at http://npg.nature.com/ reprintsandpermissions/

Publisher's note: Springer Nature remains neutral with regard to jurisdictional claims in published maps and institutional affiliations.

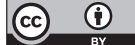

Open Access This article is licensed under a Creative Commons Attribution 4.0 International License, which permits use, sharing, adaptation, distribution and reproduction in any medium or format, as long as you give appropriate credit to the original author(s) and the source, provide a link to the Creative Commons license, and indicate if changes were made. The images or other third party material in this article are included in the article's Creative Commons license, unless indicated otherwise in a credit line to the material. If material is not included in the article's Creative Commons license and your intended use is not permitted by statutory regulation or exceeds the permitted use, you will need to obtain permission directly from the copyright holder. To view a copy of this license, visit http://creativecommons.org/ licenses/by/4.0/

(c) The Author(s) 2018 